\title{
Conceptualising Sustainable Leadership
}

\section{Abstract}

\section{Purpose}

Literature encompassing Sustainable Leadership and developing leaders sustainably are still in infancy (Lambert, 2011). Nevertheless indications identify leadership as a vital cog in achieving sustainable organisations. Sustainable leadership can allow a fast, resilient response which is competitive and appealing to all stakeholders (Avery and Bergsteiner, 2011). Arguably, organisations' need to stop considering leadership as a control function (Casserley and Critchley, 2010; Crews, 2010) and instead focus on dialogue and mutual-interdependency between leaders and their followers (Barr and Dowding, 2012). This paper aims to explore and analyse the concept of sustainable leadership to present a conceptual framework surrounding sustainable leadership.

\section{Design/methodology/approach}

This conceptual paper will review the existing frameworks of sustainable leadership and present a conceptualisation of the frameworks. This conceptualisation synthesises frameworks and literature surrounding the concept of sustainable leadership which involves work from seminal authors Casserley and Critchley (2010), Avery and Bergsteiner (2011), Hargreaves and Fink (2006), Davies (2009) and Lambert (2011). Seminal themes from the synthesised frameworks are presented to explore and unify the conceptualisation of sustainable leadership.

\section{Findings}

Within leadership literature, stakeholder approaches (Groves and LaRocca, 2011; Avery and Bergsteiner, 2011a); discourses underlining the importance of relationship between leaders and followers (Barr and Dowding, 2012); and discussions about the need to develop reflexive and participative leadership models (Kopp and Martinuzzi, 2013) have become prominent. Sustainable leadership embraces all of these new components. The concept advocates organisations should shift emphasis from a 
traditional singular focus on finances, to a view that organisations are contributors to wider environmental and social influences (Crews, 2010; Avery and Bergsteiner, 2011a).

\section{Originality/value}

This paper explores the theoretical frameworks which surround sustainable leadership and will synthesise and present commonly referenced facets of the concept within the internal and external factors influencing sustainable leadership framework. 


\section{Introduction}

A noticeable, recent trend in leadership literature has emerged towards embracing person centred and resource based views of leadership. Alongside this context many commentators have identified the need for more long lasting approaches to leadership practices (Avery and Bergsteiner, 2011b). In the aftermath of the global financial crisis organisations' are seeking more secure, stable growth through more progressive and long term approaches to leader and follower development (Kantabutra and Saratun, 2013).

There has been a lot of discussion of a need for a new paradigm of leadership development within organisations (Hewison and Griffiths, 2004; Casserley and Critchley, 2010; Crews, 2010). Nevertheless, organisations have failed to take notice of the possibilities and opportunity to change their perspective on leadership and adopt successful leadership development opportunities (Crews, 2010). Arguments suggest organisations need to stop considering leadership as a control function (Casserley and Critchley, 2010; Crews, 2010) and instead focus on dialogue and the idea of mutualinterdependency between leaders and their followers (Avery and Bergsteiner, 2011a; Barr and Dowding, 2012). Within leadership literature, stakeholder approaches (Groves and LaRocca, 2011); discourses underlining the importance of relationship between leaders and followers (Barr and Dowding, 2012); and discussions about the need to develop reflexive and participative leadership models (Kopp and Martinuzzi, 2013) have become prominent which sustainable leadership embraces. The concept advocates organisations should shift emphasis from a traditional singular focus on finances, to a view that organisations are contributors to wider environmental and social influences that exist (Casserley and Critchley, 2010; Crews, 2010; Avery and Bergsteiner, 2011a).

This paper explores emerging literature on sustainable leadership and seminal themes derived from frameworks in order to develop a conceptual framework. As the concept of sustainable leadership is still in infancy stage (Lambert, 2011), there are few guiding frameworks/models operationalising sustainable leadership. Moreover, Crews (2010) underscores the reality that there are limited empirical studies dealing with sustainable leadership to date. 


\section{Introducing Sustainable Leadership}

The theory of sustainable leadership has developed in interest and importance as a result of the fallout of the economic crisis. In defining the concept Avery and Bergsteiner (2011:5) posit;

"Sustainable Leadership requires taking a long-term perspective in making decisions; fostering systematic innovation aimed at increasing customer value; developing a skilled, loyal and highly engaged workforce; and offering quality products, services and solutions".

This definition is supplemented by the emphasis that "Sustainable Leadership practices reflect good management, often lower costs, [whilst] enhancing reputation and brand" (Kantabutra and Saratun, 2013:363). These authors adopt an organisational perspective to develop such practices; however other authors' contemplate an individualistic interpretation, whereby a focus is taken on developing individual leaders' sustainably (Casserley and Critchley, 2010).

Several sources contemplate differing perspectives when discussing the notion of 'sustainability' and this has proven to be a vital consideration in how organisations operationalise the concept. In this regard, it has been argued that sustainable leadership practices allow a fast, resilient response which is competitive and appealing to stakeholders (Avery and Bergsteiner, 2011a). Sustainability is the founding principle of sustainable leadership and the goals of the concepts align.

Although the business case for sustainable leadership proposes numerous advantages of adopting the paradigm, Avery and Bergsteiner (2011a) caution that some commentators propose it is an idealistic and humanistic approach which has been ignored and by-passed in the past. Even so, it is clear that current assumptions encompassing leadership must expand beyond its singular pursuit of profit maximisation (see Avery, 2005; Avery and Bergsteiner, 2011; Casserley and Critchley, 2010; and Tuan, 2012). Hence the creation of propositions such as the triple bottom line has signalled a shift in business philosophy. A goal of sustainable leadership is ultimately to ensure that organisations' build on their present situation towards a 
viable successful future, which involves focusing on the long-term and more than just financial success (Hargreaves, 2007).

The definitions that exist on sustainable leadership highlight a number of characteristics and facets underpinning the concept. Therefore although one singular definition cannot be applied, key similarities exist which will be explored within the conceptual framework.

\section{Frameworks of Sustainable Leadership}

Sustainable leadership has been applied in a number of different settings and contexts. Hargreaves and Fink (2006), Davies (2007) and Lambert (2011) explore sustainable leadership by adopting an organisational level of analysis in the education sector (in the US and UK). Avery and Bergsteiner (2011) adopt an organisational perspective in a number of contexts. Finally, Casserley and Critchley (2010) focus on the development of sustainable leaders from an individual perspective. It has been emphasised that;

"...there is no one 'right' way within the overall sustainable leadership paradigm" (Avery and Bergsteiner, 2011b:5)

Throughout the differing frameworks there are a number of reoccurring themes which merit consideration. The themes can be separated into people and organisational processes. Within the people elements aspects of development opportunities for both leaders and employees occurs, which includes succession planning. Also inclusion and depth are important considerations, sustainable leadership should be embedded throughout the organisation while fostering individuals, their development and resourcefulness must extend to the organisational practices; which includes development, balancing objectives while enhancing the future of the organisation. 
Table 1 outlines the commonly used frameworks of sustainable leadership. It identifies some of the key practices and characteristics of sustainable leadership as advanced by leading authors which have examined the concept. The paper utilises these to underpin a conceptual framework of sustainable leadership, analyse the seminal themes and discuss implications.

\section{Table 1: Sustainable Leadership Frameworks}

\begin{tabular}{|c|c|c|c|c|c|}
\hline \begin{tabular}{|l|} 
Author(s) \\
discussing \\
Sustainable \\
Leadership \\
\end{tabular} & Casserley and Critchley (2010) & Avery and Bergsteiner (2011) & Hargreaves and Fink (2006) & Davies (2009) & Lambert (2011) \\
\hline Definitions & $\begin{array}{l}\text { "Performance derives from an } \\
\text { integration of three core processes: } \\
\text { reflecton on action; psychological } \\
\text { intelligence; and physiological well- } \\
\text { being...it is the integration of these } \\
\text { three core processes, followed by } \\
\text { their engagement with the culture of } \\
\text { the organisation, which constitutes } \\
\text { effective leadership development, } \\
\text { generates sustainable leaders, and is } \\
\text { more likely to create sustainable } \\
\text { organisations" (p.290) }\end{array}$ & $\begin{array}{l}\text { "Sustainable leadership helps an } \\
\text { organisation endure over time and } \\
\text { weather the inevitable storms that } \\
\text { best an enterprise" ( } p .7) \\
\text { "Sustainable leadership emerges } \\
\text { from the interplay of many } \\
\text { factors... there is no one 'right' way } \\
\text { within the overall sustainable } \\
\text { leadership paradigm" (p.5) }\end{array}$ & $\begin{array}{l}\text { "The image of the future places } \\
\text { different and more challenging } \\
\text { demands on leadership. It now } \\
\text { becomes leadership for learning, } \\
\text { leadership by learning, and } \\
\text { leadership as learning" (2011:19) }\end{array}$ & $\begin{array}{l}\text { "Sustainable leadership can be } \\
\text { considered to be made up of the } \\
\text { key factors that underpin the } \\
\text { longer-term development of the } \\
\text { school. It builds a leadership } \\
\text { culture based on moral purpose } \\
\text { which provides success that is } \\
\text { accessible to all" (p.11) }\end{array}$ & $\begin{array}{l}\text { "If sustainable leadership } \\
\text { is to have any } \\
\text { measureable impact on } \\
\text { the organisation, it needs } \\
\text { commitment from all } \\
\text { elvels of the organistion } \\
\text { to create a cultre in which } \\
\text { leadership skills can be } \\
\text { developed" (p.145) }\end{array}$ \\
\hline \begin{tabular}{|l} 
Framework \\
presented \\
surrounding \\
Sustainable \\
Leadership
\end{tabular} & $\begin{array}{l}\text { 1. Reflecton on Action } \\
\text { 2. Psychological Intelligence } \\
\text { 3. Physiological Well-being } \\
\text { 4. Engagement of core processes } \\
\text { with the culture of the organisation }\end{array}$ & $\begin{array}{l}\text { Foundation Practices } \\
\text { 1. Developing people; } \\
\text { 2. Labour relations; } \\
\text { 3. Retaining staff; } \\
\text { 4. Succession planning; } \\
\text { 5. Valuing staff; } \\
\text { 6. CEO and top team; } \\
\text { 7. Ethical Behaviour; } \\
\text { 8. Long or short term perspective; } \\
\text { 9. Organisational Change; } \\
\text { 10. Financial markets orientation; } \\
\text { 11. Responsibility for environment; } \\
\text { 12. Social Responsiblity (CSR); 13. } \\
\text { Stakeholder consideration; } \\
\text { 14. Vision's role in the business } \\
\text { Higher Level Practices } \\
\text { 15. Decision making } \\
\text { 16. Self-Management } \\
\text { 17. Team Orientation } \\
\text { 18. Culture } \\
\text { 19. Knowledge-sharing and } \\
\text { retention } \\
\text { 20. Trust } \\
\text { Key Performance Drivers } \\
\text { 21. Innovation } \\
\text { 22. Staff Engagement } \\
\text { 23. Quality }\end{array}$ & $\begin{array}{l}\text { 1. Depth - Sustainable Leadership } \\
\text { matters. } \\
\text { 2. Length - Sustainable leadership } \\
\text { lasts } \\
\text { 3. Breadth - Sustainable } \\
\text { leadership spreads } \\
\text { 4. Justice - sustainable leadership } \\
\text { does no harm to and actively } \\
\text { improves the surrounding } \\
\text { environment } \\
\text { 5. Diversity - Sustainable } \\
\text { leadership promotes cohesive } \\
\text { diversity } \\
\text { 6. Resourcefulness - sustainable } \\
\text { leadership develops and does not } \\
\text { deplete material and human } \\
\text { resources } \\
\text { 7. Conservation - sustainable } \\
\text { leadership honors and learns from } \\
\text { the best of the past to create an } \\
\text { even better future }\end{array}$ & $\begin{array}{l}\text { 1. Outcomes not just outputs. } \\
\text { 2. Balancing short and long term } \\
\text { objectives } \\
\text { 3. Processes not plans } \\
\text { 4. Passion } \\
\text { 5. Personal humility and } \\
\text { professional will } \\
\text { 6. Strategic timing and strategic } \\
\text { abandonment } \\
\text { 7. Building capacity and creating } \\
\text { involvement } \\
\text { 8. Development of strategic } \\
\text { measures of success } \\
\text { 9. Building in Sustainability }\end{array}$ & 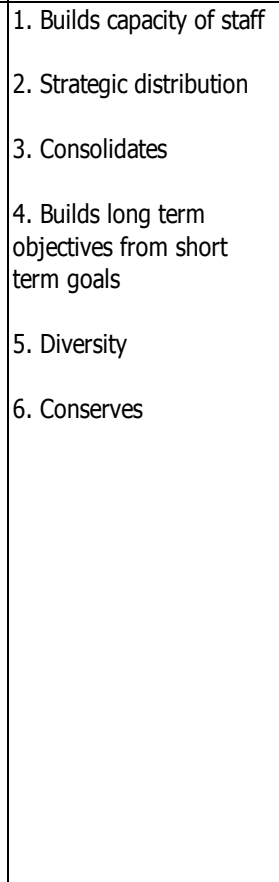 \\
\hline Perspective & $\begin{array}{l}\text { Individual perspective - } \\
\text { Focus is developing sustainable } \\
\text { leaders }\end{array}$ & $\begin{array}{l}\text { Organistional perspective - } \\
\text { Adopt a holistic view and believe it } \\
\text { is the way in which an organisation } \\
\text { is lead that leads to sustainability }\end{array}$ & $\begin{array}{l}\text { Organisational perspective - } \\
\text { Emphasise sustainability should } \\
\text { be viewed as a meal not a menu }\end{array}$ & $\begin{array}{l}\text { Organisational perspective - } \\
\text { Believes that sustainable } \\
\text { leadership should be embedded } \\
\text { throughout the organisations } \\
\end{array}$ & $\begin{array}{l}\text { Organisational Perspective } \\
\text { - Predominantly considers } \\
\text { the development of } \\
\text { Sustainable Leadership }\end{array}$ \\
\hline $\begin{array}{c}\text { Research } \\
\text { Context }\end{array}$ & $\begin{array}{l}\text { Private Sector - No real empirical } \\
\text { research has been completed on } \\
\text { sustainable leadership - really } \\
\text { developed from the idea of burnout } \\
\text { and the development of individuals }\end{array}$ & $\begin{array}{l}\text { Private sector research - exploring } \\
\text { the different 'honeybee' and 'locust' } \\
\text { organisations - comparing them and } \\
\text { producing the pyramid }\end{array}$ & $\begin{array}{l}\text { Education sector - looking at } \\
\text { research from both the UK and } \\
\text { the US and stems from the idea of } \\
\text { principle leadership }\end{array}$ & $\begin{array}{l}\text { Education Sector - looking at both } \\
\text { UK and US }\end{array}$ & $\begin{array}{l}\text { Education Sector - looking } \\
\text { at both UK and US }\end{array}$ \\
\hline
\end{tabular}




\section{Internal and External Factors Influencing Sustainable Leadership}

Following the conceptualisation of the synthesised sustainable leadership frameworks internal and external factors influencing sustainable leadership have been derived.

This conceptualisation demonstrates the different elements and factors which ultimately impact on the sustainable culture and sustainable leadership of an organisation. By developing this sustainable leadership conceptualisation, links can be made between literature and possible implications of sustainable leadership explored.

As depicted in figure 1, the three boxes within the conceptualisation (stakeholder considerations, organisational processes and the external environment) all demonstrate a grouping of factors which is essential for achieving sustainable culture and sustainable leadership. This paper will explore these considerations in depth to outline the emphasis of each facet in these elements.

Figure 1: Sustainable Leadership Conceptualisation

Stakeholder Considerations

- Improving the Internal environment

- Coherent and Cohesive Values

- Full Stakeholder Consideration

\section{External Environment}

- Recession

- Globalisation

- Public Processes

Organisational Processes

- Development of Employees throughout the Organisation

- Short versus long-term objectives and strategies

- CSR and Ethical Behaviour 


\section{Stakeholder Considerations}

Understanding the diverse interests of stakeholders whilst ensuring a sustainable employment relationship can be imperative to effective long-term organisational performance (Paauwe, 2009; Francis et al., 2012; Barr and Dowding, 2012). Holbeche (Francis et al., 2012) stresses sustainable outcomes are achieved more often in organisations where employees are engaged, motivated and healthy whilst organisational performance exist as central considerations; although the emphasis must be on all stakeholders. This can depend on the cohesion that is felt throughout the organisation; the internal environment must arguably be effective and developmental in nature for sustainable leadership to be developed and achieved (Hargreaves and Fink, 2011).

Sustainable leadership arguably builds on elements of the leader member exchange theory due to the importance placed the stakeholder and relationship aspects; which are essential in the implementation and success of sustainable leadership. Bennis (2007) emphasises the inter-related aspects that play a dynamic role in the leaders' position in organisations, arguing leadership is a tripod and relationships are crucial. However this ideology although emphasising the inter-links between stakeholders, conversely, seems to portray the leader and follower as cogs in a machine rather than complex entities which many authors argue must be a consideration within today's organisations (Crews, 2010; Groves and LaRocca, 2011). As a result, Ewen et al. (2013) extend the importance of social connections and propose the perception and understanding of social relationships as having the greatest impact. The dyadic relationship with all stakeholders and the way in which this impacts organisational effectiveness and goal achievement is crucial within organisations (Yulk, 2013). The ideology of sustainable leadership advocates inclusion (Hargreaves and Fink, 2006) and emphasises the social element of the relationship, and does not just focus on the outcomes.

Extending this theme of inclusion, Davies (2009) and Hargreaves and Fink (2006) emphasise the role of not only building capacity of employees but also involving employees in dialogue surrounding building a successful future and ensuring social inclusion and cohesion is achieved (Lambert, 2011). Nance (2008) argues that 
collegiality, dependence and barrier-less communication are pivotal elements in ensuring successful teamwork can be achieved. Additionally, the relationship between leaders and employees can be viewed as crucial for enhanced leadership (Barr and Dowding, 2012) and organisational performance. The stakeholder considerations of sustainable leadership encompass this as stakeholders play a fundamental role during decision making of the organisation (Avery and Bergsteiner, 2011). Trust impacts on many organisational processes and must play a pivotal role in sustainable leadership; particularly in relation to the transparency and relationship with stakeholders (Kang and Hustvedt, 2013).

Lueneburger and Goleman (2010) and Szekely and Knirsch (2005) emphasise the ideology of integrating sustainable leadership practices throughout the organisation originates from the sustainability underpinnings of the concept; all seminal authors highlight the importance of embedding the practices. The values of the organisation should play a vital role in sustainable leadership and these should be aligned with every practice of the organisation. Additionally to be effective the values of the organisation should be brought to life by employees who live the values and achieve the organisational goals. Therefore sustainable leaders must ensure they portray these values while combining and evidencing them in their leadership practice. Although individual leaders' should champion the sustainable leadership strategy (Hargreaves and Fink, 2006; Davies, 2009), it is imperative that the principles and practices extend beyond just the individual (Lambert, 2011). Moreover, Lambert (2011) and Hargreaves and Fink (2006) suggest that sustainable leadership should be treated like a meal rather than a menu, where organisations must take a full approach to the concept and expect the full range of advantages to be available from implementing the entirety of the concept. Thus the recognition of the importance of values and their integration is crucial throughout the sustainable leadership literature.

Lambert (2011) and Hargreaves and Fink (2011) also postulate that sustainable leadership should honour the past and present in order to develop the future; hence adopt the principles of sustainability. Subsequently, organisations should embrace lessons from the past in order to shape future development which arguably creates 
this sustainable environment within the organisation. This extends to the development of organisational processes as well as the development of stakeholder considerations.

\section{Organisational Processes}

A number of the sustainable leadership frameworks (see table 1) indicate learning and development should be inclusive and have opportunities for employees from throughout the organisation. This is accentuated by the ideology of building capacity and resourcefulness, which again, emphasises opportunities should be available for all employees (Hargreaves and Fink, 2006; Davies, 2009; Lambert, 2011).

Consequently sustainable leadership advocates the importance of both individual and leader development which should be embedded throughout the organisation (Lambert, 2011). Within todays organisations' developing employees and leaders is of the utmost importance. Garavan et al (2007:41) summarise;

"...organisations are now increasingly concerned with ensuring that their employees have the competencies and skills to be effective in the changing context (demand for improved quality and efficiency along with strict financial controls and increased accountability)"

Arguably, succession planning plays a major role in recognising, rewarding and developing talent from the early stages in employees' careers and succession planning plays a major role within sustainable leadership (Hargreaves and Fink, 2006; Davies, 2009; Casserley and Critchley, 2010; Avery and Bergsteiner, 2011; Lambert, 2011). Garavan et al. (2007) argue employees (particularly in the Irish context) consider training and development to be important. Significant characteristics of strategic HRD are participation, involvement and support along with information and communication (Garavan et al., 2007). These characteristics of HRD align with the practices of sustainable leadership which emphasises that stakeholders should be involved in all decision making processes and should pay various roles; including employees, line managers and top managers.

The concept of sustainable leadership, unlike traditional leadership concepts does not advocate a certain style, list of behaviours or traits of individual leaders and therefore the development of sustainable leadership can be diverse. The concept can be viewed 
as applying the fundamentals of sustainability to the organisation, individuals and their followers. Hargreaves and Fink (2006) discuss the ideology of resourcefulness and argue leaders' energy should be conserved and renewed; not burnt out or depleted as many leaders within todays organisations' are (Casserley and Megginson, 2008). This aligns with the framework of developing sustainable leaders by Casserley and Critchley (2010) who argue sustainable leaders are essential to sustainable organisations. However, as we can see there are more elements to consider when implementing sustainable leadership within organisations. Nevertheless the ideology of conserving and renewing individuals is fundamental to sustainability and therefore can be successfully aligned with sustainable leadership and employees' development throughout the organisation.

Sustainable leadership can and has also been described as a 'humanistic' view of leadership (Avery and Bergsteiner, 2011a). Therefore it views the leader and their role within the organisation as more important than the actual skills/qualities or characteristics of individuals within leadership positions (Hargreaves and Fink, 2006; Davies, 2007). Thus, arguably it can be applied to people in formal or informal positions and therefore should be integrated throughout the organisation. Nevertheless, Lambert (2012) emphasises leadership development and development opportunities should be undertaken on an organisational level. This is due to the fact these facets must be equal and implemented throughout the organisation, not on an individual level; where for example only 'high flyers' or 'elites' may be selected. This can and must be a vital issue for organisations to consider when undertaking sustainable leadership principles and practices within organisations. The ideology of inclusion and fairness is important to consider when implementing such sustainable initiatives.

"The literature on sustainability and corporate social responsibility has not paid much attention so far to how leaders enact a corporate sustainability strategy among organisational members" (Morsing and Oswald, 2009:83)

Corporate social responsibility (CSR) literature surrounding sustainable leadership advocates embedding the practices throughout the organisation. However there is no exact detail on how to incorporate this into organisations. Bratton and Gold (2012) 
emphasise ethics underscores the corporate social responsibility of organisations and also how far an organisation will be accountable to wider stakeholders. Again trust between the organisational leaders and stakeholders is imperative. Garavan et al., (2010) discuss that successful CSR programmes depend on enlightened employee management and leadership; an aspect also advocated by the CIPD. Arguably this could be due to the way in which ethical responsibilities and behaviour is adopted by people and not the organisation itself (Bratton and Gold, 2012:47).

Business cases for CSR advocate the strong successful correlation CSR has with the triple bottom line due to the fact that it focuses on the social, environmental and economic benefits. However an important consideration must be made regarding the integration of these concepts, as many organisations manage them separately to unsuccessful outcomes (Henriques and Richardson, 2004). Bratton and Gold (2012) expand the discussion of the triple bottom line and consider the pursuit of a quadruple bottom line performance; which they emphasise involves balancing goals of economic, environmental, social and cultural goals. The inter-dependency of the goals and elements highlighted by both Henriques and Richardson (2004) and Bratton and Gold (2012) are also vital considerations for Sustainable Leadership.

\section{External Environment}

The linkages and interdependency of ethical responsibilities, corporate governance and the external environment is important when considering the integration and development of sustainable leadership. Within this paper the people and processes elements which effect sustainable leadership and touched upon areas of the context, however as Garavan et al., (2007:74) indicate;

\section{"Context plays a vital role in determining the effectiveness of strategic HRD"}

Therefore a consideration of not only the context of implementation of sustainable leadership must be made, but the external context deliberations are as important.

Kalshoven et al. (2011:53) highlight that sustainable leadership is growing in importance and discuss Hargreaves and Fink's $(2004,2006)$ ideology of a theoretical outtake of Sustainable Leadership; 
"They suggest sustainability entails focusing on the development of others in the environment, distribution of responsibilities, and endurance over time"

Ferdig (2007) agrees and emphasises the responsibility of leaders to act beyond their self-interests. Kalshoven et al. (2011) highlight that previous research has demonstrated that the impacts of ethical leadership imply a positive relationship between the leader and employees. It is important to caution that a consideration of context is important when conceptualising sustainable leadership. Hargreaves (2007) proposes;

"Sustainable leadership should be vigilant, constantly 'scanning' the environment to check for deterioration in the conditions in which the institution operates"

Arguably the processes of CSR and corporate governance are in place to ensure the safety and the sustainability of an organisation, whilst ensuring any risks are diverted. Nevertheless, the sustainable leadership literature emphasises that a culture of sustainable leadership must also constantly ensure that, as individuals, conditions implemented and services provided are at the highest level possible. Within 'mainstream' literature many authors discuss a shift from the shareholder view of organisations to a consideration of stakeholders, however this also involves the debate surrounding short and long term objectives and which should be of primary concern.

As discussed previously sustainable leadership can be viewed as a humanistic approach to leadership which may be seen as another leadership fad. However sustainable leadership advocates what many authors have previously contented; e.g. a developmental culture is essential, succession planning is a must, coherent and cohesive values are embedded, to name a few. Thus sustainable leadership, although a 'new approach' to leadership overall contains historical elements and places them in a context and practice which can have significant improvements for organisations. Nevertheless, the move to this new approach must be an imperative implication of the concept.

Within the economic recession many organisations have resorted to a short-term approach to their objectives and strategies; or a 'locust' approach as advocated by Avery and Bergsteiner (2011). However the long-term and sustainable nature of 
sustainable leadership encourages a balance between the short- and long-term objectives/strategies of organisations. As Davies (2009) contends achieving shortterm goals can be a predictor of long-term success and therefore they shouldn't be viewed as contradicting elements but rather work towards one another. Lambert (2012) agrees and emphasises sustainable leadership won't provide short term fixes but rather a longer term trajectory for the organisation. He disagrees with the proposition that short and long term objectives are incompatible, and highlights that rather they should be used to complement one another and with sustainable leadership this could be achieved (Lambert, 2012). Avery and Bergsteiner (2011) indicate that adopting a long term perspective is central to sustainable leadership. Consequently we can conclude that sustainable leadership overall focuses on building a sustainable long-term future for the organisation. With that said though short-term goals can arguably lead us towards this sustainable future.

Also, the movement to a focus of all stakeholders of the organisation can be seen as a priceless element of sustainable leadership, particularly due to the psychological contracts that exists between the organisation and third parties (such as employees). Sustainable leadership does place huge importance on the social aspects of leadership within organisations which cannot be a risk and can only achieve successful outcomes.

Public processes can be a huge concern for many organisations, including in particular public sector companies and many question how a long-term plan can be built if Governments and/or policies change. When considering the values of public sector organisations the idea of changing policies is crucial to consider along with the impact this has on the processes and values of the organisation. However further examination needs to be made as to how these changes from the external environment impact the internal environment and therefore the leadership and culture of this environment.

\section{Implications for Research and Practice}

There are a number of implications for research and practice to consider as a result of the conceptual framework presented in this paper which will be reviewed. The presentation of the internal and external factors influencing sustainable leadership 
allows a clear understanding of the multi-faceted components organisations must consider which allows a contention of the implications for research and practice.

The successful implementation of sustainable leadership arguably depends on an effective sustainable culture within the organisation and how this is affected by the external environment. It has been suggested that "leadership is entwined with culture formation" (Barr and Dowding, 2012:65) and therefore arguably the leadership of an organisation can hugely impact its culture. A pivotal argument here is the role and development of employees and leaders which must be central to an organisation's sustainable success. If there is not a culture of development and conservation within an organisation then the underpinnings of sustainable leadership are crucially missing. As has been identified there are a number of components and considerations of sustainable leadership presented throughout literature, however the conceptual framework aims to present an encompassing, coherent framework for organisations to understand and utilise.

Nevertheless the operationalization of sustainable leadership could be questionable. Although the conceptual framework presented in this paper depicts the considerations organisations must make. It doesn't directly address how organisations will operationalise the concept. The difficulties of this arise around the clarifications and directions organisations must make relating to what the concept can mean to them directly. Avery and Bergsteiner (2011b) present the sustainable leadership pyramid which can be used as a diagnostic tool by organisations to identify which leadership practices they have in place, and which are missing. However as this paper highlights there are other frameworks of sustainable leadership which have additional considerations of the concept. Therefore context must play a pivotal role in how an organisation can operationalise the concept and although this paper aims to clarify and aid understanding of sustainable leadership, it does not seek a one-size-fits-all approach. Consequently the operationalization of sustainable leadership within different contexts can be an area of future research, including the public sector which is yet to be fully considered. 
Another implication to consider is the way in which it will be implemented in practice which will differ greatly. As with the context the decision and arguably the leadership in organisations will differ. Therefore the implementation of sustainable leadership can be diverse. Although the facets and factors of the concept will be the same their approach and achievements can be significantly different. Take the values of an organisation, these may be strong and motivating for employees though not part of their daily routine and therefore employees can be out of touch with them. Whereas, if the values of the organisation are embedded throughout practices and policies of the organisation this can make a huge difference. Consequently components such as these can be problematic as although they are vital within sustainable leadership, it is not a 'tick box' type exercise and it must be continually enhanced and reminded throughout the organisation.

\section{Conclusion}

This paper has explored the theoretical frameworks which surround sustainable leadership and has synthesised and presented commonly referenced facets of the concept within the internal and external factors influencing sustainable leadership. This allows a coherent depiction of the concepts considerations to be made and analysed. The implications to be considered include the operationalization of sustainable leadership in practice as although the theoretical dimension is covered, the way in which different organisations under the sustainable leadership practices. On the other hand, the change in culture and approach to leadership can be significant and although there are noteworthy advantages of sustainable leadership; it can be seen as a long-term approach which can take time to implement. Therefore organisations must proceed towards a sustainable culture and sustainable leadership can encompass this by ensuring that the greatest number of practices have been achieved. 


\section{References}

Avery, G. C. \& Bergsteiner, H (2011a), "Sustainable Leadership Practices for Enhancing Business Resilience And Performance", Strategy \& Leadership, Vol.39, No.3, pp.5-15.

Avery, G. C. \& Bergsteiner, H. (2011b), Sustainable Leadership: Honeybee And Locust Approaches, Oxon: Routledge.

Avery, G. C. (2005), Leadership for Sustainable Futures: Achieving Success in a Competitive World, Edward Elgar: London.

Barr, J., and Dowding, L. (2012), "Leadership in Health Care", $2^{\text {nd }}$ ed. London: Sage Publications Limited.

Bennis, W. G., \& Nanus, B. (2007), Leaders: The strategies for taking charge, New York: HarperCollins.

Bratton, J., and Gold, J. (2012), "Human Resource Management: Theory and practice", $5^{\text {th }}$ ed. Hampshire: Palgrave Macmillan.

Casserley, T. \& Critchley, B. (2010), "A New Paradim Of Leadership Development. Industrial and Commercial Training", Vol.42, pp.287-295.

Casserley, T. \& Megginson, D. (2008), Learning From Burnout: Developing Sustainable Leaders And Avoiding Career Derailment, Oxford: Elsvier.

Crews, D.E. (2010), "Strategies for implementing sustainability: Five leadership challenges", SAM Advanced Management Journal, Vol.75, No.2, pp. 15-21.

Davies, B. (Ed.) (2007), Developing Sustainable Leadership, London, Sage Publications.

Ewen, C., Wihler, A., Blickle, G., Oerder, K., Ellen III, B.P., Douglas, C., and Ferris, G. R. (2013), Further specification of the leader political skill-leadership effectiveness relationships: Transformational and transactional leader behavior as mediators, The Leadership Quarterly, Vol.24, No.4, pp.516-533.

Ferdig, M.A (2007), Sustainability Leadership: Co-creating a Sustainable Future, Journal of Change Management, Vol.7, No.2, pp.25-35. 
Francis, H., Holbeche, L., and Reddington, M. (2012), People and Organisational Development: A new agenda for organisational effectiveness, London: Chartered Institute of Personnel and Development.

Garavan, T., N., Heraty, N., Rock, A., and Dalton, E. (2010), Conceptualising the behavioural barriers to CSR and CS in organisations: A typology of HRD Interventions, Advances in Developing Human Resources, Vol.12, No.5, pp.587-613.

Gavavan, T., Gubbins, C., Hogan, C., and Woodlock, M. (2007) "Transitioning to a strategically aligned HRD function: The case of a health services organisation", in Sambrook, S., and Stewart, J. (Ed.), Human Resource Development in the Public Sector: The case of health and social care, Oxon: Routledge.

Groves, K.S., and LaRocca, M.A. (2011), "An Empirical Study of Leader Ethical Values, Transformational and Transactional Leadership, and Follower Attitudes Toward Corporate Social Responsibility", Journal of Business Ethics, Vol.103, No.4, pp.511528.

Hargreaves, A., and Fink, D. (2011), 'Succeeding Leaders: Supply and Demand' In: White, R.E., and Cooper, K. (eds.) Principals in Succession: Transfer and Rotation in Educational Administration. [online] Available at: http://ezproxy.napier.ac.uk:3718/static/pdf/459/bok\%253A978-94-007-12751.pdf?auth66=1383925785 f5e8ef634ba18f62d23680f5222db5f4\&ext=.pdf [Accessed $6^{\text {th }}$ November 2013] [DOI: 10.1007/978-94-007-1275-1_3]

Hargreaves, A., and Fink, D. (2006), Sustainable Leadership, San Francisco: Jossey Bass.

Hargreaves, A. (2007), "Sustainable Leadership and Development in education: creating the future, conserving the past", European Journal of Education, Vol.42, No.2, pp. 223-233.

Henriques, A., and Richardson, J., (2004) (Eds), "The Triple Bottom Line: Does it all add up? Assessing the sustainability of business and CSR", London: Earthscan. 
Hewison, A. and Griffiths, M. (2004), "Leadership development in health care: a word of caution", Journal of Health Organization and Management, Vol.18, No.6, pp.464 473

Kalshoven, K., Den Hartog, D.N., and De Hoogh, A.H.B. (2011), "Ethical leadership at work questionnaire (ELW): Development and validation of a multidimensional measurement", The Leadership Quarterly, Vol.22, No.1, pp.51-69.

Kang, J., and Hustveat, G. (2013), "Building trust between consumers and corporations: The role of consumer perceptions of transparency and social responsibility", Journal of Business Ethics, [online] DOI: 10.1007/s10551-013-1916-7

Kantabutra, S., and Saratun, M. (2013) Sustainable leadership: Honeybee practices at Thailand's oldest university. International Journal of Educational Management, 27 (4), pp. 356-376.

Kopp, U., and Martinuzzi, A. (2013), "Teaching sustainability leaders in systems thinking", Business Systems Review, Vol.2, No.2, [online] DOI: 10.7350/BSR.V10.2013.

Lambert, S. (2012) The perception and implementation of sustainable leadership strategies in further education colleges. Journal of Leadership Education, 11 (2), pp. 102-119.

Lambert, S. (2011). Sustainable leadership and the implication for the general further education college sector. Journal of Further and Higher Education, 35 (1), pp.131-148. Lueneburger, C. and D. Goleman (2010), The change leadership sustainability demands, MITSloan Managment Review, Vol.51 No.4 pp.1-7.

Morsing, M. and D. Oswald (2009), Sustainable leadership: management control systems and organisational culture in Novo Nordisk A/S, Corporate Governance, Vol.9 No.1, pp.83-99.

Nance, J.J. (2008), Why hospitals should fly: the ultimate flight plan to patient safety and quality care, Bozeman: Second river healthcare press. 
Northouse, P.G. (2013), Leadership: Theory and Practice, $6^{\text {th }}$ ed., London: Sage Publications.

Paauwe, J. (2009), "HRM and Performance: Achievements, methodological issues and prospects", Journal of management studies, Vol.46, No.1, pp.129-142.

Szekely, F. and M. Knirsch (2005), "Responsible leadership and corporate social responsibility: Metrics for sustainable performance", European Management Journal, Vol.23, No.6, pp.628-647.

Tuan, L.T. (2012), "An air-flight ticket agency with sustainable leadership", Journal of management and sustainability, Vol.2, No.1, [online] DOI: 10.5539/jms.v2n1p210.

Yulk, G. (2013), Leadership in Organisations, $8^{\text {th }}$ ed., Essex: Pearson Education Limited. 